\title{
O TEMPO COMO ENREDAMENTO DA EXPERIÊNCIA: ORFEU E O OBSTÁCULO DA LEMBRANÇA ${ }^{1}$
}

TIME AS A BIND OF EXPERIENCE:

ORPHEUS AND THE OBSTACLE OF REMEMBRANCE*

\author{
Vanessa Vasconcelos \\ Claudia Helena Gonçalves Moura \\ Kety Valéria Simões Franciscati. \\ da Universidade Federal de São João Del-Rei.
}

\section{RESUMO}

Neste artigo, empreende-se uma análise das relações historicamente estabelecidas entre indivíduo e cultura, tendo como eixo orientador a categoria do tempo, a partir do qual se analisam os elementos que vêm enredando a experiência e impedindo o devir da lembrança. Busca-se o auxílio em outra área de conhecimento, o mito, no que este pode trazer de elucidação das relações históricas de domínio entre indivíduo, cultura e tempo, bem como das possibilidades não realizadas pela cultura. Para isso, recorre-se ao Mito de Orfeu e à maneira pela qual Marcuse analisa a imagem de Orfeu como libertador, ao se servir de indícios de um tempo distinto de sua solidificação dada em uma cultura regida pela lógica da dominação. Estabelece-se também um diálogo com as considerações de Horkheimer e Adorno a respeito desta problemática.

Palavras-chave: Teoria Crítica da Sociedade. Formação Cultural. Mito. Subjetividade.

Trata-se de uma situação simples, um fato a contar $e$ esquecer.

Mas se alguém comete a imprudência de parar um instante a mais do que deveria, um pé afunda dentro $e$ fica-se comprometido. Desde esse instante em que também nós nos arriscamos, já não se trata mais de um fato a contar, começam a faltar as palavras que não o trairiam.

[...] E pessoas precisam tanto poder contar a história delas mesmas.

Clarice Lispector

Em todo seu movimento histórico, o mito é tomado por Horkheimer e Adorno (1985) como esclarecimento, no sentido de tentar desvelar as tendências ocultas da natureza para que, assim, o homem possa libertar-se, de alguma forma, do medo pela natureza desconhecida. Essa tentativa de desvelamento da natureza deu-se historicamente como uma busca de explicações dos fenômenos por meio de poderes ocultos de divindades que foram criadas e projetadas na natureza pelos homens em seu processo de constituição. Por essa configuração, os mitos são considerados modelos

*Artigo recebido em 30/06/2009 e aprovado em: 19/10/2009 
morais, apontando, assim, para a história da relação entre indivíduo, cultura e natureza (CROCHÍK, 2000). Nesse sentido, o diálogo que aqui se tenta estabelecer com o conhecimento proveniente da mitologia procura indicar tanto os limites presentes na narrativa mitológica como também considerar os vestígios deixados por ela que possam contribuir para um possível desvelamento das barreiras que vem impedindo o estabelecimento de uma subjetividade autoconsciente e autodeterminada na contemporaneidade. Desse modo, do mesmo modo como os teóricos frankfurtianos, tomam-se os mitos tanto em seu potencial de esclarecimento como em seu caráter ideológico, tendo em vista uma melhor compreensão da cultura e, assim, das relações que nela se estabeleceram historicamente.

Nesse sentido, recorremos a um objeto da mitologia grega para este estudo - o mito de Orfeu - com o objetivo de analisar determinados caracteres ideológicos presentes na cultura, colocando em evidência alguns conflitos imanentes à constituição desta e como eles vêm impedindo uma possível experiência por parte do indivíduo que se encontra entranhado na cultura. Esses conflitos se dão entre natureza e indivíduo, entre indivíduo e cultura e com a tentativa de autonomia frente à heteronomia existente. Por dentro destes conflitos, encontra-se um elemento: o tempo, que no indica tanto a possibilidade de experiência quanto a sua impossibilidade, dada a forma como se encontra organizado na sociedade, ou seja, de maneira solidificada, impedindo, assim, uma possível experiência por parte dos indivíduos, uma vez que a estes se encontra interditada a possibilidade de recordar seu passado.

O personagem mítico de Orfeu parece designar o papel de indicar o fracasso da cultura: em seu próprio fracasso, reside o intento de ultrapassar as barreiras repressivas impostas pela sociedade, de não se deixar subjugar por seus imperativos. Desse modo, a partir das reflexões dos autores da chamada Teoria Crítica da Sociedade, toma-se aqui o mito de Orfeu como subsídio para a investigação do aprisionamento histórico do indivíduo enquanto enredamento ${ }^{2}$ da experiência e impossibilidade da lembrança. $\mathrm{O}$ indivíduo, com efeito, estando sob um tempo administrado em uma cultura estruturada por uma razão dominadora, vem encontrando poucos indícios de uma vida satisfatória.

Assim, pretendemos contribuir para se pensar a adesão do indivíduo aos aspectos repressivos da cultura. Isso se faz em contraposição com a imagem de Orfeu, que, no contexto mítico, de acordo com a perspectiva de Marcuse (1975), pode ser entendida como uma reação em prol da gratificação, resguardando o funcionamento da memória naquilo que condiz com a lembrança - resistência e possibilidades de transformação, indícios de uma vida que poderia basear-se na experiência.

\section{A DEIFICAÇÃO DO TEMPO}

O tempo, como o espaço, é uma categoria criada pelo homem para organizar-se como existente, podendo ser entendido como um meio facilitador de nomear o próprio conhecimento do ser e do mundo. A partir disso, pode-se detectar a imanência do ser humano ao movimento de existir no tempo, já que suas determinações estão inteiramente ligadas ao fato de nascer e morrer. O existir é um passar, o que é característico daquilo mesmo que pôde ser nomeado como tempo, tornando-se este o próprio estado em que o homem se encontra mergulhado. No entanto, à medida que a sociedade incorporou em seu sistema modelos de dominação e repressão - que se tornaram inscritos nas categorias de espaço e de tempo -, vem exigindo cada vez mais a submissão do homem à sua ordem, já que, segundo Marcuse (1975, p.13), 
[...] a sociedade afluente depende cada vez mais da ininterrupta produção e consumo do supérfluo, dos novos inventos, do obsoletismo planejado e dos meios de destruição, fazendo com que os indivíduos se adaptem a esses requisitos de um modo que excede os caminhos tradicionais.

A adaptação do homem a esses requisitos faz com que ele se encontre em um estado de automutilação tanto física como mental. $O$ que a sociedade exige como pré-requisito para a manutenção de si mesma é que o indivíduo viva em função do tempo da produção, estipulado por ela por meio de sacrifícios e de renúncias, ressaltando que esse tempo está mais para um não tempo, um massacre do coletivo sobre o particular, devido à supremacia da demanda de se ser veloz. Essa supremacia da velocidade torna-se visível no fato de o homem encontrar-se constantemente no desespero de ver a vida esvaindo-se pelos segundos corridos do relógio. É, pois, a maior causa da angústia que se sente pela aproximação da morte, já que, segundo Crochík (2009, p.59) "a rapidez é resposta desesperada a poder morrer no segundo seguinte, é o medo de não ter tempo para concluir a tarefa".

Assim, o tempo, como ressalta Marcuse (1975), vem sendo o maior aliado que a sociedade tem na manutenção da lei e da ordem vigentes, ajudando o homem a esquecer o que foi e o que pode ser, negando totalmente o passado e voltando-se apenas a um amanhã pré-determinado. De maneira peculiar, o filósofo Agostinho (1987, p.218) já problematizava a existência de um tempo tripartido, no qual já imperava certa supremacia de um presente enredado pela reificação:

De que modo existem aqueles dois tempos - o passado e o futuro -, se o passado já não existe e o futuro ainda não veio? Quanto ao presente, se fosse sempre presente, e não passasse para o pretérito, já não seria tempo, mas eternidade. Mas se o presente, para ser tempo, tem necessariamente de passar para o pretérito, como podemos afirmar que ele existe, se a causa da sua existência é a mesma pela qual deixará de existir?

No entanto, resguardadas as diferenças das reflexões entre os autores aqui trabalhados, Adorno (1993) indica ser o tempo da experiência aquele que permite a reunião do passado e do futuro no presente, de modo a quebrar com a ordenação do tempo da produção, no qual a duração do instante é sentida como um sacrilégio diante do horror a que vem se reduzindo a vida.

Supondo o tempo como passado, presente e futuro, nota-se uma exigência por parte do sistema, que se dê a renúncia a estes preceitos. No momento em que se relega o tempo da experiência em prol do tempo dos relógios, o homem torna-se cego a ponto de ver no ato de retornar ao passado algo relativo a uma regressão. Não percebe, porém, que as rédeas de sua vida são tomadas pelo passado, uma vez que nesse ritmo alucinante, o presente vem sendo um simples fantoche utilizado pela manifestação de um pretérito fracassado, sobre o qual não se pode refletir. Assim, o sujeito, ao negar o passado, vive, ao contrário, totalmente sujeito a este no sentido de não estar consciente da importância do mesmo em relação à aspereza em que se encontra no presente.

É nesse sentido que o não render ao tempo é muitas vezes visto como um ato sobrenatural diante da situação na qual nos encontramos, visto que imersos na lógica da dominação que tem como alicerces a velocidade e o progresso regidos pelo princípio do desempenho ${ }^{3}$, tornamos nossa vida um constante sacrifício.

No entanto, como seria possível romper com o ciclo do tempo sólido e enrijecido em um mundo regido pela lógica da dominação? O enrijecimento do tempo, 
ainda que tenha seu poder abalado pela lembrança como possibilidade de se resgatar o passado, não cede muito espaço a um triunfo da liberdade. A lembrança, enquanto necessário movimento da subjetividade, não é por si só suficiente, uma vez que o relembrar, segundo Marcuse (1975), será uma verdadeira tentativa contra a dominação apenas se traduzido em ação histórica.

O passado, como um dos maiores prisioneiros do tempo, sobre o qual não se pode ainda refletir, vem justificando ações humanas repletas de ódio e terror, o que significa que as feridas contidas no passado não foram e nem serão esquecidas, já que deixaram marcas profundas na constituição do indivíduo. Marcuse (1975, p.200) expressou-se bem ao dizer que "[...] esquecer o sofrimento passado é perdoar as forças que o causaram - sem derrotar essas forças", ressaltando que, de uma forma ou de outra, essas forças acabam voltando.

Desse modo, a memória remete à lembrança da historicidade, do passado em si. Entretanto, o princípio a que estamos subjugados relega a humanidade a um viver sem memória, já que a ida ao passado vem significando uma ameaça ao sistema social, pois neste movimento se teria a possibilidade de reflexão e de um possível respirar frente à opressão na qual o indivíduo se encontra. Adorno (1995a, p.36) aponta para o impacto da racionalidade dominante sobre a esfera subjetiva:

de qualquer modo, a ideologia dominante hoje em dia define que, quanto mais as pessoas estiverem submetidas a contextos objetivos em relação aos quais são impotentes, ou acreditam ser impotentes, tanto mais elas tornarão subjetiva esta impotência.

Isso quer dizer que quanto menos os indivíduos tiverem tempo, mais eles incorporarão essa racionalidade irracional ${ }^{4}$, ficando vedado qualquer indício de experiência, até mesmo pelo ingênuo relembrar. Dessa forma, é pela organização do tempo em torno da organização social do trabalho que a cultura adquire domínio sobre o indivíduo e este responde, com certo conformismo, através da adaptação sem resistência alguma à expansão ao ritmo da esfera da racionalidade produtiva. Assim, o sistema social, tomando o tempo como um poderoso aliado para as tramas da administração total, exerce um controle de tal forma no indivíduo que, ainda que lhe imponham qualquer tipo de regra, até aquelas que exigem uma extrema renúncia de seu próprio eu, ele acaba por aderir àquilo mesmo que o faz sofrer. Isso indica o comprometimento de uma subjetividade autônoma na atualidade.

O princípio da moralidade civilizada ${ }^{5}$ regida totalmente para a recordação de deveres, como bem lembra Marcuse (1975), provoca uma organização sólida no tempo, de tal forma que a vida passa a ser guiada por uma pressão aniquiladora. O homem, assim, vive uma angústia extrema em relação à impotência sentida e ocasionada pelo impacto de instituições totalitárias consubstanciado na solidificação do tempo. Nesse contexto, podemos dizer que o tempo, em certo sentido, vem tornando-se vilão da vida. Adorno (1993, p.145) explana distintamente sobre essa posição opressiva adotada pelo tempo:

nesse estado de completa impotência, o indivíduo percebe o tempo que lhe resta para viver como o quarto de hora concedido antes da execução. Ele não espera viver de si sua vida até o fim. A perspectiva de morte violenta e martírio, presente a cada um, prolonga-se na angústia de saber que os dias estão contados e que a duração da própria 
vida está submetida à estatística; que envelhecer tornou-se uma espécie de vantagem [...]. Essa angústia é registrada pelo corpo na fuga das horas. O tempo voa.

Assim, torna-se evidente também a condição extrema de morte na qual o homem se encontra: uma total violência, que acaba denunciando a realidade repressiva. E é justamente pelo fato de a morte ter algo de revelador - nos indicar o quanto não estamos vivendo, o quanto estamos aprisionados - que a cultura ocupa-se em persuadir os homens a repudiá-la, como se esse repúdio estivesse intrinsecamente ligado ao homem. Desse modo, o tempo e a morte tornam-se aliados na cultura vigente, no sentido de se impor a repressão através do medo que a morte gera, de tal modo que o tempo se reduz à função de apontar a gradual aproximação do indivíduo para a morte.

Nessa situação, o homem, sentindo-se ameaçado por estar sob a premência da morte e encontrando-se diante do fato de ter tido uma vida que não foi vivida como deveria, depara-se com o desespero e o ódio frente à situação reveladora: a de se ter tido até então uma vida sem sentido, percebida, na verdade, como uma traição a si mesmo, pois, ainda que sob a tentativa de guardar para si o passado tentando esquecê-lo, esse ressurge como prova da traição que acaba por se traduzir na ruína de sua vida. A partir disso, cabe uma ressalva sobre a relação do homem com a morte: "em face dos mortos os homens desabafam o desespero de não serem mais capazes de se lembrarem de si próprios" (HORKHEIMER \& ADORNO, 1985, p.202).

\section{ORFEU E SEU CONTEXTO MITOLÓGICO: FRACASSO E RASTROS DE RECONCILIAÇÃO}

Há uma considerável importância de situar o contexto mitológico em que Orfeu se encontra, já que seus "ancestrais" dizem muito de suas características e, conseqüentemente, de suas ações, que são descritas na narrativa mítica.

Na mitologia, Zeus e a deusa Mnemosyne (personificação da memória) tiveram nove filhas, sendo as nove, musas. Dentre as nove, Kalliópe (Belavoz), mãe de Orfeu, é a mais importante delas. Segundo Hesíodo (1992), as musas tinham o poder de manutenção da vida e do ser, por assegurar e configurar a ordem, mantendo o Olimpo (morada dos deuses) pela força de seu canto. Havia uma aliança entre o canto, a presentificação por meio dele, e a ordem estabelecida. As musas cantavam o presente, o futuro e o passado.

Podemos considerar a ida ao passado, a lembrança, como uma possível etapa de reflexão do homem em seu processo de constituição como indivíduo, ou seja, de sua história como um caminho fundamental e imanente à formação. Entretanto, para a lembrança liberar o passado e a memória da petrificação imposta pelo existente, ressaltamos seu necessário caráter de superação da mera autopreservação: não se trata de voltar-se a algo em meio a padrões defensivos que congelam o contato com os objetos, mas de ir para, seguir em todas as direções ao encontro dos objetos, movimento de abertura que presentifica a história como experiência - o sofrer o outro para além da maldição da individuação (FrANCiSCATTI, 2005). Assim, a ida ao passado de forma alguma significaria apenas um encontro diante da negação da vida, um estar presente em uma vida já mortificada pelo tempo, mas também, de se poder recordar aquilo que já foi esquecido, tendo como possibilidade alguma transformação: a liberação da práxis do aprisionamento que arrasta a vida como um mero sacrifício.

Não poderia ser por menos que Orfeu é filho da Musa mais importante, já que as características herdadas - o dom da música, e o estabelecimento de uma ordem através 
desta, a aliança entre presente, passado e futuro - são demonstradas em seu próprio mito. Segundo Brandão (2003, p. 141), Orfeu tangia a lira e a cítara de tal forma que "os animais selvagens o seguiam, as árvores inclinavam suas copadas para ouvi-lo e os homens mais coléricos sentiam-se penetrados de ternura e bondade."

Por estas características, Marcuse (1975) considera Orfeu um artista - músico e poeta - que simboliza uma realidade diferente desta vivida: sua imagem mítica traz aspectos importantes que negam aquilo que representa uma ordem social alicerçada na mais-repressão ${ }^{\mathbf{6}}$, que indicam a superação, por meio de sua arte, da oposição reificada entre natureza e homem, sujeito e objeto. Ele inspira a instauração de uma ordem sem se utilizar de meios dominadores, configurando assim uma ruptura das repressões, em que razão e sensualidade não são movimentos contraditórios e excludentes entre si, mas complementares.

Como consta na obra de Brandão (2003), ao voltar da expedição dos Argonautas, Orfeu conhece a Ninfa Eurídice a quem acaba devotando amor profundo e se casando. $\mathrm{O}$ apicultor Aristeu persegue Eurídice tentando violá-la, porém esta, ao sair correndo com o propósito de fugir, pisa em uma serpente, que a pica, causando-lhe a morte. Segundo o mito, Eurídice desaparece na morada dos mortos (Hades) e Orfeu, não conformado com o que se passara - a perda brutal de parte daquilo que o movia à vida -, sem hesitar, desce à morada das sombras a fim de trazê-la de volta à vida, encantando todos que se encontravam no submundo, através de sua voz divina e sua cítara.

Esta recusa de Orfeu à morte súbita e violenta pode ser entendida, com base em Marcuse (1975), como atitude de negação de uma civilização que vem, conforme a especificidade de seu momento histórico, desenvolvendo-se sob o princípio repressivo. Com esta atitude, Orfeu parece mostrar sua não resignação frente a uma vida de não satisfação, de não realização, calcada permanentemente na violência.

Diante de tal empreendimento, ele se depara com a única regra imposta pelos deuses do Hades; a condição para Orfeu conseguir o que queria era única:

[...] ele seguiria à frente, e Eurídice lhe acompanharia os passos, mas, enquanto caminhassem pelas trevas infernais, ouvisse o que ouvisse, pensasse o que pensasse, Orfeu não poderia olhar pra trás, enquanto o casal não transpusesse os limites do império das sombras. (BRANDÃO, 2003, p.142.)

Entretanto, segundo a narrativa mítica, pode-se dizer que Orfeu desconfiou que aquilo que desejava poderia estar enredado em uma armadilha da ilusão, ou seja, tomado por uma extrema inquietação olhou para trás, não se deixando levar pela conformidade de que Eurídice poderia não estar lá.

Assim, podemos argumentar que ele se encontrava sob a ameaça do tempo, a passagem do momento de plenitude, a angústia sob a aproximação do fim. Contudo, ao negar o monopólio do tempo enfrentando-o, ele também enfrentou a submissão à ordem e à renúncia. O olhar para trás é tomado pela cultura, ao longo das diferentes épocas, como um fracasso, um retrocesso; porém, ao contrário dessa perspectiva, de acordo com Marcuse (1975), esse olhar para trás diz de um princípio de realidade não-repressivo, que não mais o submeteria à constante espera da realização de seu desejo.

Dessa forma, como exposto, neste caso olhar para trás não pode ser entendido como um retrocesso, mas denúncia do princípio de realidade repressivo, ou seja, daquela realidade que impõe o caminhar sempre em frente, sem vacilo algum, 
suportando a angústia do não se poder olhar para trás, de conformar-se com a possibilidade de não ter o seu desejo realizado.

É interessante o movimento feito por Orfeu de ir contra aquilo que a cultura emprega: o domínio da ação em detrimento dos desejos. No entanto, há na narrativa mítica, uma clareza obscura de que Orfeu não cumpriria com a regra imposta pelos deuses do Hades: ele não havia cumprido ordem ou imposição alguma desde o começo. Desse modo, o que nos faria supor que ele não olharia para trás? Talvez uma conformidade, como membros desta cultura, com o princípio estabelecido que vigora desde aquela época? Ou ainda, no relato mítico haveria a oportunidade de exemplificar o que acontece com aqueles que, em meio à fragilidade interna que não agüenta a invasão avassaladora dos sentidos e a turbulência da razão contestadora, desobedecem? Ao olhar para trás, Orfeu parece não apontar o seu fracasso, mas sim o nosso fracasso de supor (e até mesmo afirmar) que ele não olharia para trás, o que então denuncia o quanto estamos presos à máxima de seguir sempre em frente em uma caminhada angustiante na qual não restam muitas possibilidades de se responder aos desejos.

Contudo, em meio a várias indagações que possamos trazer a respeito de tal passagem, o que constatamos é que Orfeu fracassou em seu intento. Assim, como conta Brandão (2003), ao transgredir a ordem dos soberanos das trevas, Orfeu voltou-se para trás e viu Eurídice, que se esvaiu para sempre em uma sombra, morrendo pela segunda vez. Orfeu ainda tentou regressar ao submundo, mas o barqueiro Caronte não mais o permitiu.

Distante de empreender uma análise analógica do mito, pela qual se buscariam semelhanças entre o mito e fenômenos psíquicos atuais, tal como Freud realizou em sua teoria, ressalta-se que estamos tomando o mito, com base em Crochík (2000), como testemunho histórico das relações entre cultura e natureza bem como entre o indivíduo e a cultura. Uma vez que, segundo este autor, o mito contém um ideal de relações valorizado pela cultura, sendo, assim, portador dos interesses desta, torna-se necessário analisar seu conteúdo ideológico no que ele traz de reafirmação da ordem vigente.

Sob essa ótica, a punição sofrida por Orfeu quando intenta certa autonomia em seus atos pode ser entendida como um possível exemplo de condenação social: as atitudes de recusar a morte e, ainda, de olhar para trás quando lhe foi ordenado seguir em frente, ao se apresentarem como ameaças à manutenção de uma cultura erguida sob a dominação e perpetuada desde então sob o tempo solidificado, acabam condenadas na narrativa mítica e tomadas como o verdadeiro motivo de um destino malogrado, devendo ser, por isso, interditadas.

Nesse sentido, questiona-se se isto remeteria ao conflito ainda existente entre indivíduo e cultura agravado pelos contornos da sociedade industrial. Se o indivíduo intrinsecamente ligado a essa sociedade deve apropriar-se de seus valores para se constituir, cabe também questionar o quanto esses valores vêm requerendo somente a adaptação do indivíduo ao caráter heterônomo da cultura, restringindo qualquer possibilidade de autonomia.

Ainda após a volta do submundo, Orfeu estabelece uma ordem diferente daquela vivida pelos homens, sendo sincero a um Eros estabelecido desde então: recusa-se a abrir mão do amor libidinal por Eurídice, que considera parte de sua alma, não aceitando relacionar-se com outras mulheres, o que também pode indicar a não resignação a um contexto instaurado por uma ordem já vigente. Segundo Brandão (2004), Orfeu instituiu mistérios inteiramente vedados às mulheres. Os homens se reuniam com ele em uma casa fechada até que, uma noite, as mulheres enfurecidas 
(Mênades), ultrajadas por sua fidelidade à memória da esposa, estabelecendo outra ordem, fizeram-no em pedaços e jogaram seus restos juntamente com a cabeça no rio Hebro.

De acordo com Marcuse (1975), Orfeu pagou com sua própria vida a tentativa do estabelecimento de uma ordem diferente, rejeitando a conformidade com uma realidade de violência e repressão, regida pelo princípio do desempenho, em prol de uma ânsia presentificada, da lembrança de uma possível reconciliação entre a busca de satisfação e a realidade.

\section{O TABU DE ORFEU}

Em continuidade à análise empreendida até então, torna-se pertinente tecer mais algumas considerações sobre o mito de Orfeu, a fim de ressaltar o quanto a análise desse mito pode contribuir para a compreensão da problemática do tempo, tal como este organizou-se historicamente numa cultura que avança sob a égide da dominação. Podemos dizer do mito de Orfeu como um tabu, no sentido em que Adorno (1995b, p. 98) o compreende, como uma "[...] sedimentação coletiva das representações, e que acabaram perdendo sua base real". A própria maneira como ele é visto pela cultura já mostra essa sedimentação: Orfeu é tomado como alguém que não cumpriu as regras desde o começo e, por ter agido desse modo, foi punido, tornando-se claro pelo mito que não se deve ultrapassar as regras da cultura.

O próprio ato de mutilar Orfeu realizado pelas Mênades pode revelar, em si, a grande contradição que permeia as condições que deveriam acolher a vida dos homens, existindo, nestes termos, somente duas escolhas: ou o indivíduo mutila seu eu em prol de um aparente apaziguamento com o sistema instaurado e o tempo nele vigente, ou ele é mutilado pelo sistema por não agir conforme lhe dita a ordem. Encontrando-se nesse beco, só lhe resta o desespero de viver subjugado a um sistema, ou a tentativa de revolta contra aquilo que lhe é imposto. Orfeu escolhe a segunda opção, recusando-se a aceitar qualquer tipo de subordinação ao que é imposto pela mais-repressão da civilização.

o mostrar que regras podem ser quebradas a partir do momento em que há uma implicação naquilo que se faz, Orfeu sabia que perderia algo - seu objeto de amor - ao romper com a ordem de não olhar para trás (ida ao passado). Porém, havia um propósito pretendido em sua não-aceitação, propósito de se preservar de tudo aquilo que a subordinação a essa cultura do progresso vem trazendo consigo como o tempo solidificado, a dominação dos sentidos, a castração de uma satisfação apaziguada, a cegueira do sofrimento, dentre infinitas outras.

Segundo os autores frankfurtianos, o homem, para ser livre, não pode ser escravo dos sentidos nem da razão. Seria esse o dilema que Orfeu enfrenta e mostra ao quebrar a ordem de olhar apenas para frente, ordem imposta por Plutão e Perséfone no mito e que também se estende pela cultura na atualidade? Uma vez que, ao que tudo indica, nos encontramos em uma aterrorizante e constante situação de pressão social, a qual vem exigindo o progresso em um ritmo totalmente acelerado que não deixa brechas para se ir para (para todas as direções, em especial, para o passado, para as lembranças), tal dilema encontraria condições mais objetivas na contemporaneidade?

É difícil para o homem entranhado na cultura que progride nesses termos aceitar essa possibilidade que Orfeu traz. Certos aspectos que subjazem nesse mito parecem estar obnubilados: diante do impacto de seu fracasso e obstados do contato com sua própria fragilidade, os homens tendem a portar-se mais como uma caricatura do 
pensamento por estar este imerso na lentidão e no obscurecimento. Nesse terreno, grassa o repúdio ao fracasso e aos fracassados, tal como aparece desde os discursos que integram O banquete, de Platão (1979). Nessa obra, mais precisamente no discurso de Fedro, condena-se Orfeu por não ter aceitado a morte tal como fizeram outros personagens míticos, louvados muitas vezes por morrerem em nome de seu amor, e ainda mais: a Orfeu atribui-se a covardia por ir a Hades em vida e a esta querer retornar com seu amor, a vergonha por fracassar, e a justa punição por esta afronta às normas.

Desse modo, a exemplo dessa passagem, a versão desse mito, que remete mais ao seu fracasso, parece preponderar e distanciar-se da interpretação apresentada por Marcuse (1975): a imagem de Orfeu como um libertador, aquele que se defrontou com os impedimentos objetivos a uma subjetividade autônoma. O confronto destas duas diferentes análises do mito pode iluminar o quanto ainda, nos dias atuais, o passado e aquilo que Orfeu representa sejam tomados como tabus: o enredamento da experiência, que leva o indivíduo a não perceber que aquilo que ganha conformando-se às imposições da cultura e do tempo administrado decorrente dela, submetendo-se a qualquer tipo de exigência em prol de um pseudoconforto, é muito menos do que ele ganharia assumindo seus sentimentos e desejos, na tentativa de não-resignação com a ordem dominadora existente.

A imagem de Orfeu como libertador rompe com o tabu de seu mito perpetuado pela ordem opressiva existente: o de que, na aceitação da morte, nunca se deve negar a imposição da cultura; que, ao não olhar para trás, nunca se deve questionar o progresso da sociedade. Assim, relembrando o fim trágico de Orfeu, torna-se pertinente falar também do risco que se assume ao se rebelar contra a ordem da dominação. No mito, o risco vivido por Orfeu, frente ao qual pagou com sua própria vida, indica a dificuldade de se resistir à ordem vigente bem como ao tempo organizado por ela. Mas, ainda que sob o medo da morte e em meio a tentativas desajeitadas por conta da transmutação do fracasso em progresso e seu conseqüente interdito, o contato - enquanto um elemento da lembrança - com o fracasso vivido pelos homens pode trazer a inscrição do fracasso dessa cultura e potencializar a sua elaboração nessas duas esferas.

Assim, outro ponto a ser ressaltado é o fato de Orfeu ser neto da memória (Mnemosyne), este fato é extremamente considerável já que, como visto anteriormente, a memória é algo que a cultura se esforça para manter sob controle, remetendo ao mínimo possível de recordações. Orfeu quebra também com essa regra, ao deixar-se virar totalmente para a rememoração: após a volta do submundo, sem Eurídice, ele recusa qualquer tipo de esquecimento (representado pelo não relacionamento com outras mulheres), se virando para a lembrança daquele amor não realizado. Desse modo, Orfeu vai contra o princípio sócio-burguês enfatizado por Adorno (1995a, p. 33):

[...] a memória, o tempo e a lembrança são liquidados pela própria sociedade burguesa em seu desenvolvimento, como se fossem uma espécie de resto irracional, do mesmo modo como a racionalização progressiva dos procedimentos da produção industrial elimina junto aos outros restos da atividade artesanal também categorias como a da aprendizagem, ou seja, do tempo de aquisição da experiência do ofício. Quando a humanidade se aliena da memória, esgotando-se sem fôlego na adaptação ao existente, nisto reflete-se uma lei objetiva de desenvolvimento.

Portanto, podemos considerar Orfeu como portador da denúncia do permanente fracasso da relação do indivíduo com a cultura, que vem utilizando-se deste para seu progresso, que, segundo Adorno e Horkheimer (1985), vem se caracterizando como o 
progresso da dominação, anulando qualquer possibilidade de experiência e, assim, impedindo a formação de uma subjetividade autoconsciente. Ao rebelar-se contra qualquer tipo de princípio limitador da cultura, contra aquilo que obsta a realização de seu projeto histórico de diferenciação, Orfeu contribui para desfazer aquela imagem da deificação do tempo administrado, pois, em vez de corroborar a manutenção da dominação alienante, tenta, pelo presente, remeter tanto a ida ao passado por meio da lembrança, como um possível vir a ser no futuro, estabelecendo alguns indícios que delineiam uma ordem não opressiva e oportuna, na qual se desse então a possibilidade da reflexão e de uma ação orientada por esta em prol da realização histórica da humanidade.

\section{ABSTRACT}

In this article, the category of time is analyzed as the axis to the historically established relationships undertaken between the individual and culture. Through this category the elements which bind experience and obstruct the formation of remembrance are analyzed. Help is sought from another field of knowledge, the myth, for the light it can cast on the historical relationships of domination between the individual, culture and time, as well as the possibilities unaccomplished by culture. Hence, the Myth of Orpheus and the way that Marcuse analyzes the image of Orpheus as a liberator, by using signs of a distinct time of its given solidification in a culture governed by the logic of domination. A dialogue is also established with Horkheimer and Adorno's considerations with regard to this issue.

Key-words: Critical theory of society. Cultural formation. Myth. Subjectivity

\section{NOTAS}

${ }^{1}$ Uma versão preliminar deste artigo foi apresentada durante o XV Encontro Nacional da Associação Brasileira de Psicologia Social, Psicologia Social e Políticas de Existência: Fronteiras e Conflitos, de 30 de outubro a 02 de novembro de 2009.

${ }_{2}^{2}$ Dentre as várias acepções permitidas pela palavra "enredamento", utiliza-se aqui este termo para designar o comprometimento da "experiência" ou da formação que, segundo Adorno (1996), converteu-se em seu contrário, a semiformação socializada, a adaptação irrestrita do sujeito a uma cultura que traiu as possibilidades de autonomia - da sua realização como lugar de liberdade e de felicidade.

${ }^{3}$ Este termo é utilizado por Marcuse (1975) para designar o princípio de uma sociedade antagônica na qual, por estar em um processo de constante expansão e de uma racionalização da dominação, encontrase instaurado o controle excessivo sobre o trabalho, que se torna, pois, um trabalho alienado que ocupa a maior parte do tempo de vida do indivíduo, eliminando qualquer resquício de gratificação.

${ }^{4}$ Segundo Horkheimer (2000), a razão tem passado historicamente por um processo de formalização, no qual tem-se reduzido a mero instrumento de adequação entre meios e fins, fins que se presumem como justificados por si próprios. À medida que abandonou a reflexão sobre a realidade e sobre as relações que o homem vem estabelecendo com esta, a razão tem aderido a quaisquer propósitos no jogo de forças sociais, sem questionar sobre seus fins - até mesmo quando esses fins negam precisamente os interesses mais racionais da humanidade.

${ }^{5}$ Segundo Marcuse (1975), o princípio da moralidade civilizada de Nietzsche assenta-se no treino da memória para a recordação de deveres e obrigações, associando-se assim à má-consciência e à culpa, ao invés de dirigir-se à busca de satisfação. Nesse sentido, subsiste na memória apenas a ameaça de punição já instaurada pela cultura.

${ }^{6}$ Para que o indivíduo se constitua socialmente, a própria realidade em que está inserido exige um considerável grau de controle sobre os instintos; a realidade, porém, vem sendo regida por um princípio dominador que introduz controles adicionais além daqueles indispensáveis à civilização humana. Esses controles adicionais são denominados por Marcuse (1975) de Mais-Repressão. 


\section{REFERÊNCIAS}

ADORNO, T. W. Teoria da semicultura. [1959]. Trad. Newton Ramos-de-Oliveira; Bruno Pucci; Cláudia B. M. de Abreu; Paula Ramos de Oliveira. Educação e Sociedade, n.56, ano XVII, p. 388-411, 1996.

O que significa elaborar o passado. [1963] In. Educação e emancipação. Trad. Wolfgang Leo Maar. Rio de Janeiro: Paz e Terra, 1995a. p. 29-49.

Tabus acerca do magistério. [1969] In. . Educação e emancipação. Trad. Wolfgang Leo Maar. Rio de Janeiro: Paz e Terra, 1995b. p. 97-117.

Minima Moralia: reflexões a partir da vida danificada. [1951]. Trad. Luiz Eduardo Bicca. 2. ed. São Paulo: Ática, 1993.

SANTO AGOSTINHO. Confissões. [400]. Trad. de J. Oliveira Santos; A. Ambrósio de Pina. 4. ed. São Paulo: Nova Cultural, 1987. In: Santo Agostinho (Coleção Os pensadores.)

BRANDÃO, J. S. Mitologia Grega. v. 2. Petrópolis: Vozes, 2003.

CROCHÍK, J. L. Adorno em ato: progresso e (in)felicidade. Revista Educação: Biblioteca do professor, São Paulo, p.56-65, fev. 2009.

Ulisses e Narciso: o abandono de si mesmo e o abandono a si mesmo. Revista Olhar. São Carlos: UFSCAR, v.2, n.4, p. 19-37, dez. 2000.

FRANCISCATTI, K. V. S. A maldição da individuação: reflexões sobre o entrelaçamento prazer-medo e a expressão literária. 231 f. 2005. Tese (Doutorado em Psicologia: Psicologia Social) - Pontifícia Universidade Católica de São Paulo, São Paulo, 2005.

HESÍODO. Teogonia: a origem dos Deuses. Trad. Jaa Torrano. 2. ed. São Paulo: Iluminuras, 1992.

HORKHEIMER, M. Eclipse da Razão [1946]. Trad. de Sebastião Uchoa Leite. São Paulo: Centauro, 2000.

; ADORNO, T. W. Dialética do Esclarecimento: fragmentos filosóficos (1947). Trad. de Guido Antonio de Almeida. Rio de Janeiro: Jorge Zahar, 1985.

MARCUSE, H. Eros e civilização; uma interpretação filosófica do pensamento de Freud. [1955]. Trad. de Álvaro Cabral. 6. ed. Rio de Janeiro: Zahar Editores, 1975.

PLATÃO. O banquete. [387-67 a.C] Trad. José Cavalcante de Souza. 2. ed. In: Platão. São Paulo: Abril Cultural, 1979. p.1-53. (Coleção Os pensadores). 
Vanessa Vasconcelos é graduanda do curso de Psicologia, aluna-pesquisadora iniciação científica - do Laboratório de Pesquisa e Intervenção Psicossocial (LAPIP) da Universidade Federal de São João Del-Rei (UFSJ). E-mail: vvanvv@msn.com

Claudia Helena Gonçalves Moura é graduada em Psicologia pela Universidade Federal de São João Del-Rei (UFSJ), mestranda do Programa de Pós-Graduação em Psicologia (PPGPSI) e do Laboratório de Pesquisa e Intervenção Psicossocial (LAPIP) da UFSJ e bolsista da FAPEMIG. E-mail: claudiahgm@yahoo.com.br

Kety Valéria Simões Franciscatti é Mestre e Doutora em Psicologia: Psicologia Social pela Pontifícia Universidade Católica de São Paulo (PUC/SP). Professora Adjunta do Departamento de Psicologia (DPSIC), professora permanente do Programa de PósGraduação em Psicologia (PPGPSI) e pesquisadora do Laboratório de Pesquisa e Intervenção Psicossocial (LAPIP) da Universidade Federal de São João Del-Rei (UFSJ). E-mail: kety.franciscatti@gmail.com 